\title{
Evaluating the Perception of Ventilation for Thermal Comfort in Senate Buildings: A Case of Nigeria Universities
}

\author{
Ayeni Conqueror A, Ayinla A. Kunle, Ajayi Oluwole \\ Ladoke Akintola University of Technology, Ogbomoso, Oyo State Nigeria \\ ayoariyoayeni@gmail.com
}

\begin{abstract}
Window condition is one of the major factors of ventilation in office buildings. The study aimed at evaluating the natural ventilation in Senate buildings of selected Universities in South-West Nigeria. The study employed the use of questionnaires survey to solicit information on subjective feelings of the occupants on the effects of thermal opening and thermal comfort in Senate buildings offices. Direct observation was carried out to obtain information on the physical characteristics of the selected buildings. Limited research has been recorded on the study of occupants' feelings in buildings in relation to openings in buildings. Based on the survey results, it was found that $34.0 \%$ of the windows were casement type, $30.0 \%$ were projected $25.5 \%$ were sliding; while $9.5 \%$ were the louvred type. The study showed that $73.8 \%$ of the respondents preferred the casement window type because of its easiness in operation to other window types and improved thermal comfort on occupants. The study concluded that with adequate sizes, casement window type is the best in ameliorating the effect of thermal discomfort in Senate Buildings.
\end{abstract}

Keywords: Senate Buildings, Casement, Louvered, South-West Nigeria, Thermal Comfort, Openings /Ventilation

\section{Introduction}

Senate Building is categorized as an Administrative building and administration are connected with organizing the work of business of an establishment. Thus, every establishment requires an administrative building to organize, run and conduct properly the overall affairs of their objectives to achieve the desired set goal. Therefore, administrative building is a place where activities are carried out to plan, organize and run a business, school or other institutions. It is also a place where the progress and success of a business, school and other institutions are controlled and determined (Fajobi, 2004). The administrative building houses the facilities that enhance the coordination of activities of the Academic Administration. Each University requires an administrative building (Senate Building) in order to achieve the goal for which the University is established, for this reason Senate building is the nerve centre of administrative and Academic Coordination of any University. Provisionally a feasible building or green building is a result of a plan which centres on expanding the effectiveness on human well-being and the environment with the life cycle of building, this could be way better accomplished through way better plan, development, operation and maintenances (Frej, 2005). This can also be achieved through the provision of appropriate openings (doors and windows). Many researchers have recommended natural ventilation as the most effective passive techniques that can aid comfort in a warm humid climate. However, there has not been much research work on natural ventilation in this climatic region.

Air movement is one of the major factors in ventilation efficiency in Office Building. Various studies of Bluyssen, 1996; Iannone, 1999, Adebamowo, 2004; Adunola, 2006; Ayinla, 2011; Ayinla, 2013 have indicated that natural air movement is generally low and the majority of the occupants felt dissatisfied with the ventilation rate within the indoor spaces. Many of the office building from observation therefore, resulted in the use of active energy system (Fans, Air Conditioner, etc) to provide indoor comfort for the occupants. The use of active energy system has been established by scholars like Bluyssen, 1996; Iannone, 1999, Adebamowo, 2004; Adunola, 2006; Ayinla, 2011; Ayinla, 2013 to be expensive and not Sustainable especially in developing Country in a warm humid climate like Nigeria. Effective Ventilation comfort in indoor space of warm humid climate, window conditions have been established to be a major factor; scholars like Bluyssen, 1996; Iannone, 1999, Adebamowo, 2004; Adunola, 2006; Ayinla, 2011; Ayinla, 2013 have recommended the use of casement windows especially in residential building to provide adequate and effective ventilation comfort. However, in Nigeria, limited research has been done on the perception of occupants for thermal comfort in buildings. This Study therefore looks at the subjective feelings of the occupants of the Senate Buildings in selected Universities in order ameliorate the effect of thermal discomfort for the occupants. 


\section{The Following Research Questions Address the Window Conditions:}

- What are the types of windows in use in Senate Buildings of south-west Nigeria University?

- What are the present conditions of opening for ventilation comfort in the study Area?

- What are the user's perceptions of the present window condition in the Study Area?

\section{Literature Review}

The literature relevant to this study can be broadly divided into four which are ventilation and its efficiency in buildings, factors affecting ventilation window and window types and case studies of existing similar buildings. This forms the theoretical framework for which the study is based. In this way, most verifiable buildings were ventilated normally, yet numerous of these have been bias or destroy by the expansion of partition dividers and mechanical frameworks. In neighbourly climates and buildings sorts normal ventilation can be utilized as a substitution to air-conditioning plants, sparing $10 \%-30 \%$ of add up to vitality utilization.

Normal ventilation frameworks depend on weight contrasts to move and incite blossoming, cool and clean discuss through buildings. Weight contrasts can be caused by wind or the buoyancy impact made by temperature contrasts or contrasts in mugginess. In each case, the amount of ventilation will depend strongly on the measure and position of openings within the building. Natural ventilation, opposite fan-forced ventilation, employs the natural powers of wind and buoyancy to provide new air into buildings. Clean air is required in buildings to all relieve and reduce odors, to supply oxygen for breathing, and to extend thermal comfort. In any case, opposite genuine air-conditioning, natural ventilation is ineffectual at decreasing the mugginess of approaching air. This lays a boundary or confinement on the application of natural ventilation in sticky climates. In addressing the ventilation condition in the study area,

Types of Natural Ventilation Effects: Thus, when the wind blows air through openings within the divider on the windward side of the building, and suck the air out of openings on the leeward side and the roof. Temperature contrasts between warm air inside and cool air outside can cause the air within the room to rise and exit at the ceiling or edge, and enter through lower openings within the divider. Moreover, buoyancy caused by contrasts in mugginess can allow a pressurized column of thick, evaporative cooled air to supply space, and lighter, hotter, muggy discuss to deplete close the best. These types of natural ventilation effects are further described below.

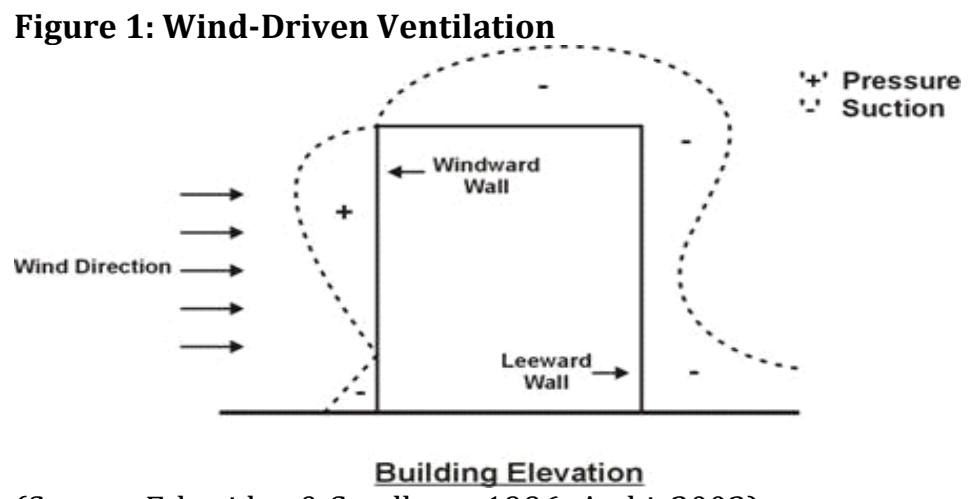

(Source: Etheridge \& Sandberg, 1996; $\underline{\text { Awbi, 2003) }}$

Wind-Driven Ventilation: As the actually happening wind blows over a building; the wind hits the windward divider causing a coordinate positive weight. The wind moves around the building and clears out the leeward divider with a negative weight, too known as a sucking impact. In the event that there are any openings on the windward and leeward dividers of the building, new air will surge within the windward divider opening and exit the leeward divider opening to adjust and palliate the weights on the windward and leeward dividers (Figure 1). 
Proposals from design rules from different building directions too propose the following:

Stack Ventilation: Buoyancy ventilation can be actuated by temperature (known as stack ventilation) or by mugginess (known as a cool tower). Typically, once you need to maximize the ventilation); Building form and measurements. (Normally ventilated buildings ought to not be as well profound since it'll be more troublesome to convey new air to all parts of the building); Window typologies and operations; characteristics of openings; Construction methods and detailing; Outside components; Urban arranging thought for stack ventilation to work appropriately when there's a temperature difference. As the warm air (as a rule given off by the inhabitants and their computers), which is less thick, within the building rises, the cooler air is sucked from the openings underneath (figure 2)

Figure 2: Stack Ventilation

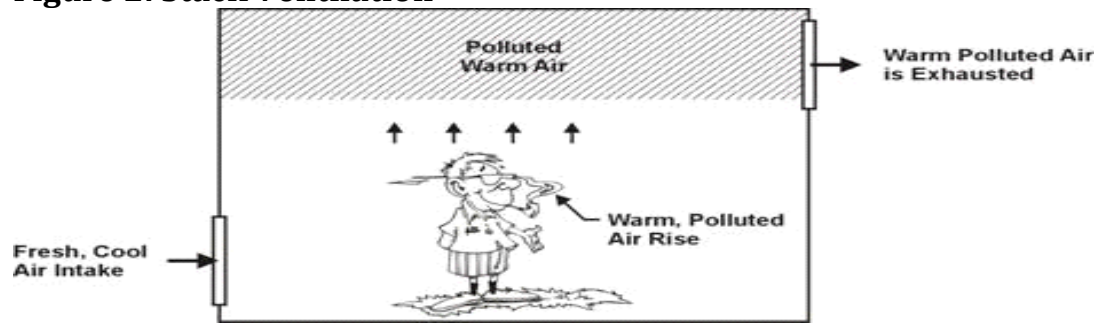

(Source: Etheridge \& Sandberg, 1996; Awbi, 2003)

Design Considerations for Stack Ventilation: Inlets ought to supply low air within the room. Exhausts ought to be found over the room and at tall level. The vertical separation between the inlet and exhaust openings ought to take advantage of the stack impact. Utilized as bay windows or edge vents. The work as fire exits of encased staircases ought to not be compromised in the event that stack ventilation is consolidated into the plan. With stack ventilation, it does not depend on the wind. On hot summer days with no wind, the normally happening stack impact can take put with the moderately steady air stream. In addition, since it does not depend on the weight and direction of the wind, there's a more noteworthy control on finding the air admissions. In any case, stack driven ventilation is constrained to a lower magnitude than wind driven ventilation. It is additionally exceptionally subordinate on the interior and exterior temperature differences Building orientation and position. (Choosing a position with a parcel of wind, building ought to be arranged so that the windward divider is opposite to the summer wind.

Elements of Building Ventilation: Ventilation moves open air into a building or a room, and disperses the air inside the building or room. The common reason of ventilation in buildings is to supplysound air for breathing by both diluting the poisons beginning within the building and expelling the toxins from it (Etheridge \& Sandberg, 1996; Awbi, 2003).

Building ventilation has three basic elements: Ventilation rate-the sum of open-air air that's given into the space, and the quality of the open air air; air stream direction-the generally wind current heading in a building, which ought to be from clean zones to grimy zones; and air conveyance or wind current design the outside air ought to be conveyed to each portion of the space in an effective way and the airborne toxins created in each portion of the space ought to too be expelled in a proficient way. There are three strategies that may be utilized to ventilate a building: natural, mechanical and hybrid (mixed-mode) ventilation, (Atkinson, 2009).

Natural ventilation: Natural powers, like: thermal buoyancy and winds constrain due to indoor and outdoor thickness contrasts, drive outdoor through purpose-built, building envelope openings. Purposebuilt openings incorporate windows, entryways, sun-powered chimneys, wind towers and stream ventilators. This natural ventilation of buildings depends on climate, building design and human conduct, (Atkinson, 2009). 
Mechanical Ventilation: Mechanical fans drive mechanical ventilation. Fans can either be introduced specifically in windows or dividers, or introduced in air channels for providing air into, or depleting air from, a room. The sort of mechanical ventilation utilized depends on climate. For case, in warm and sticky climates, invasion ought to be minimized or anticipated to diminish interstitial condensation (which happens when warm, sodden air from the interior of a building enters a divider or partition, roof or floor and meets a cold surface). In these cases, a positive weight mechanical ventilation framework is often utilized. Alternately, in cold climates, ex-filtration has to be anticipated to diminish interstitial condensation, and negative weight ventilation is utilized. For a room with locally created poisons, such as a washroom, toilet or kitchen, the negative weight framework is regularly used. An adjusted mechanical ventilation framework alludes to the framework where air supplies and depletes have been tried and balanced to meet design details. The room weight may be kept up at either marginally positive or negative weight, which is accomplished by utilizing marginally unequal supply or debilitate ventilation rates. For illustration, a slight negative room weight is accomplished by depleting $10 \%$ more discuss than the supply in a cold climate to play down the plausibility of interstitial condensation.

Hybrid or Mixed-Mode Ventilation in Buildings: Hybrid (mixed-mode) ventilation depends on normal driving powers to supply the specified (design) stream rate. It employs mechanical ventilation when the natural ventilation flow rate is as well as low. When natural ventilation alone is not suitable, deplete fans (with satisfactory pre-testing and arranging) can be introduced to extend ventilation rates in rooms lodging patients with the airborne disease. In any case, this straightforward type of hybrid (mixed-mode) ventilation has to be utilized with care. The fans ought to be introduced where room air can be depleted specifically to the open air environment through either a divider or the roof. The size and number of deplete fans depends on the focused on ventilation rate, and must be measured and tried sometime recently utilize. Issues related with the utilize of exhaust fans incorporate establishment troubles (particularly for huge fans), clamor (especially from high-power fans), expanded or diminished temperature within the room and the prerequisite for continuous power supply. If the environment within the room causes warm inconvenience spot cooling or warming frameworks and ceiling fans may be included. Plausibility is the installation of whirlybirds (whirligigs or wind turbines) that do not require power and give a roof-exhaust framework expanding wind current in a building.

\section{Research Methodology}

The research embraced four rule strategies to be specific: literature audit, questionnaire survey, Interview and case study for this study. An intensive writing hunt for either primary sources or secondary sources was conducted through scholastic research Journals, proceedings, dissertations, occasional papers, publications, textbooks, daily papers and online information. Data from the Primary source were collected with the help of research instruments such as reconnaissance survey, personal interviews and administration of questionnaires among others. Referring to previous work also enables the author to grasp the problems and issues related to the topic of the study. Preliminary investigation of the existing Senate Building in the study area was considered. This enables the researcher to get familiarize with the study area. This however helped to examine the situation in the study area. Users from the study area were interviewed in the area of natural ventilation in the built Senate Building from the Study area and their Subjective feeling to the Senate Building in general. The questionnaire was designed to obtain information on social-economic, characteristics of the respondent and building characteristic adequacy of natural ventilation in the Selected Senate Buildings and as well as the user's perception with regards to preferred window types. It will also assist to solicit information on subjective feelings of the occupants of the selected Senate buildings on the effects of openings on their body comfort. These data also include the capacity spaces and offices of the four Senate Buildings. Direct observation was also carried out to obtain information on the physical Characteristics of the Selected Senate Building. Twenty-Five users were sampled in each of the Selected Senate Buildings. There are twenty-one (21) Senate Buildings in the Universities in South-West Nigeria. This represents the sampling frame. The study randomly selected twenty percent (20\%) of the sample frame given a sample size of four (4). In each of the Selected Senate building, twenty-five users were randomly selected for questionnaire administration. A total of 100 questionnaires were therefore distributed in the study area. 


\section{Data Analysis}

Information collected was analyzed utilizing the Statistical Package for Social Sciences (SPSS version 26). This analysis includes descriptive and inferential analysis to explain the information that suits the objectives. Descriptive analysis adopted in the study include, the use of cross-tabulation, frequency count and percentage tables as well as graph presentation. All these were used to analyze the socio-economic characteristics of respondents such as gender, age marital status, and educational status among others. The wind current heading may be visualized by smoke. Computational liquid flow and molecule picture velocimetry strategies permit the air dispersion execution in a room to be modelled (Nielsen, 1974; Chen, 1996; Etheridge \& Sandberg, 1996).

\section{Observed Senate Buildings}
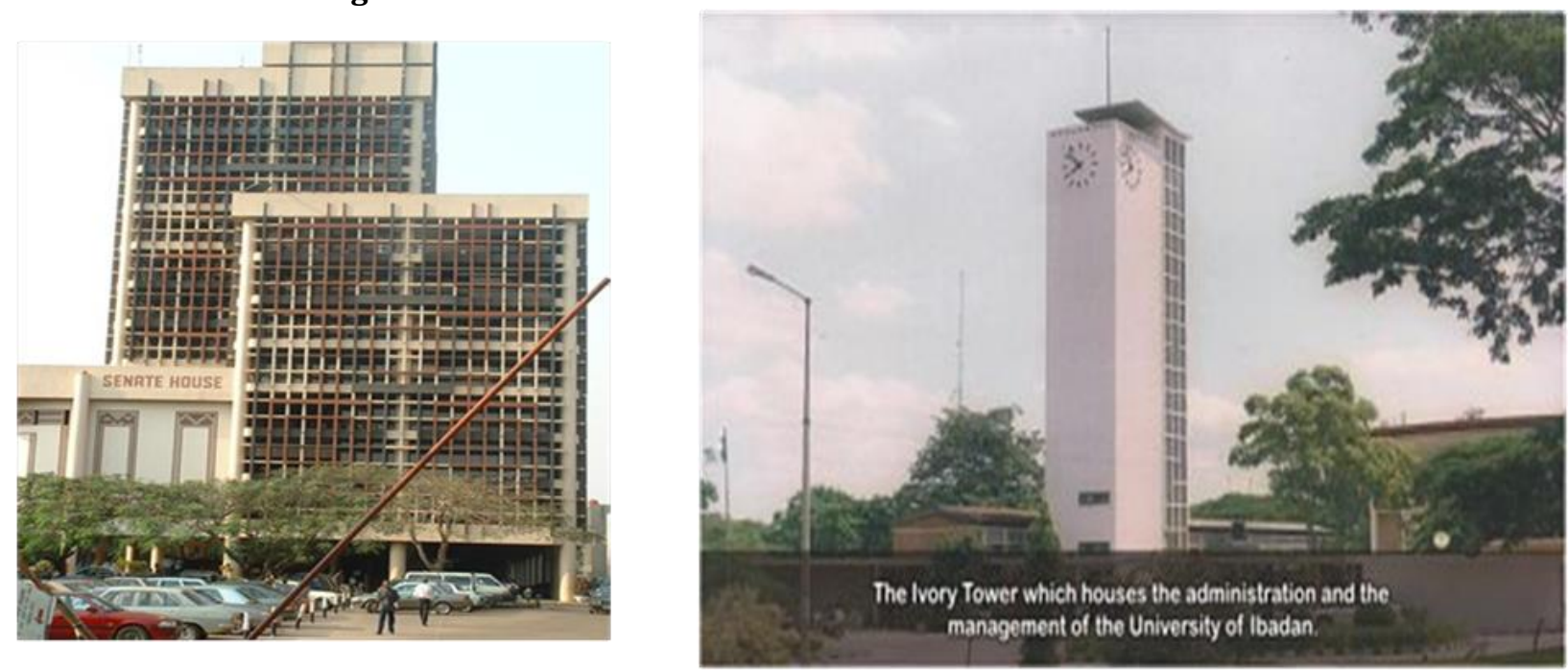

Picture showing the UNILAG Senate Building

Source: Author's Field Survey, 2017

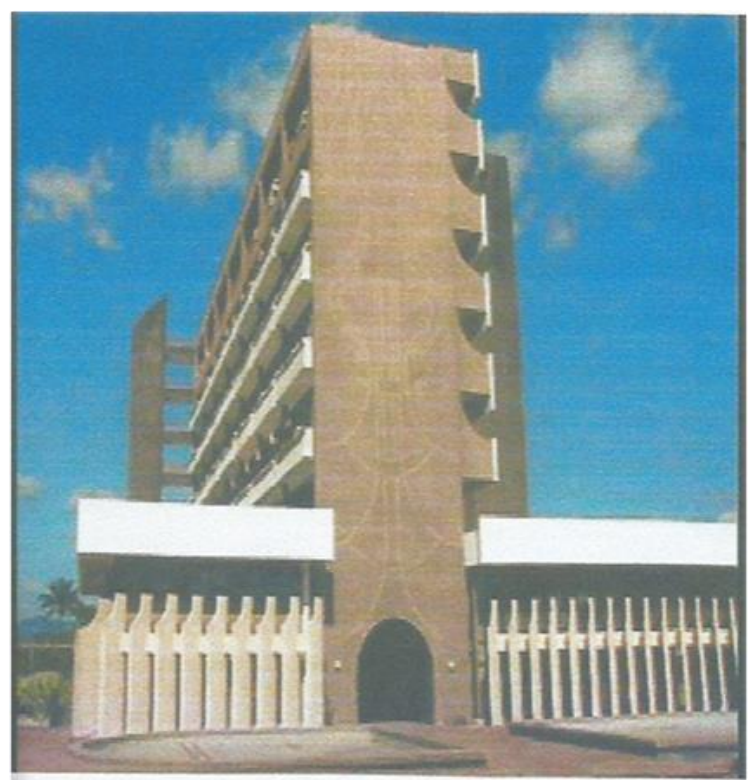

Approach Elevation of the OAU Senate Building.

Source: Author's Field Survey, 2017

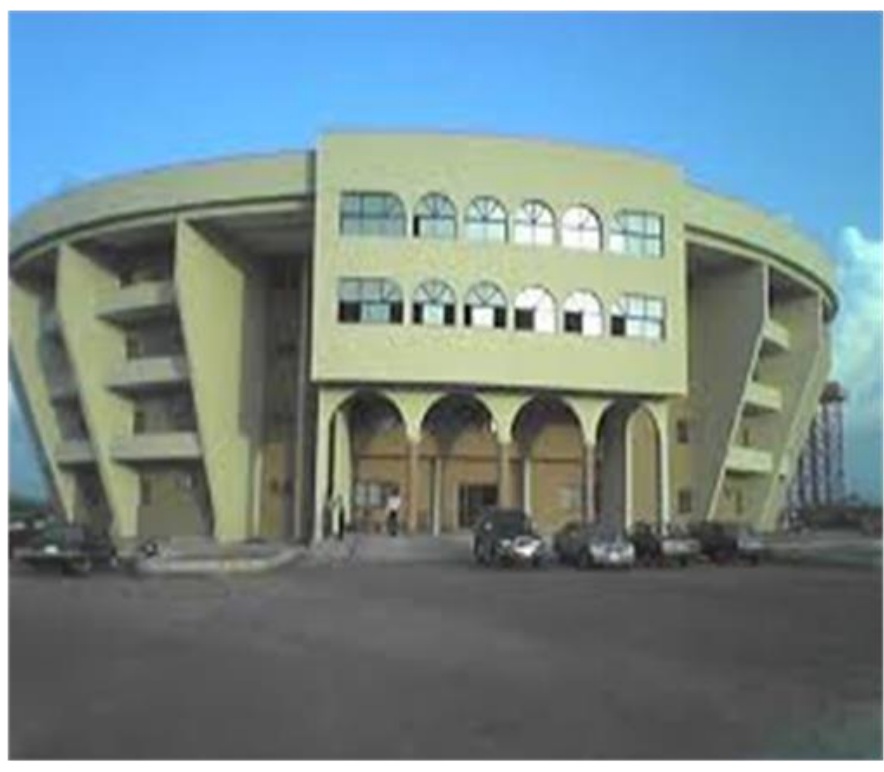

Approachview of LAUTECH Senate Building

Source: Author's Field Survey, 2017 


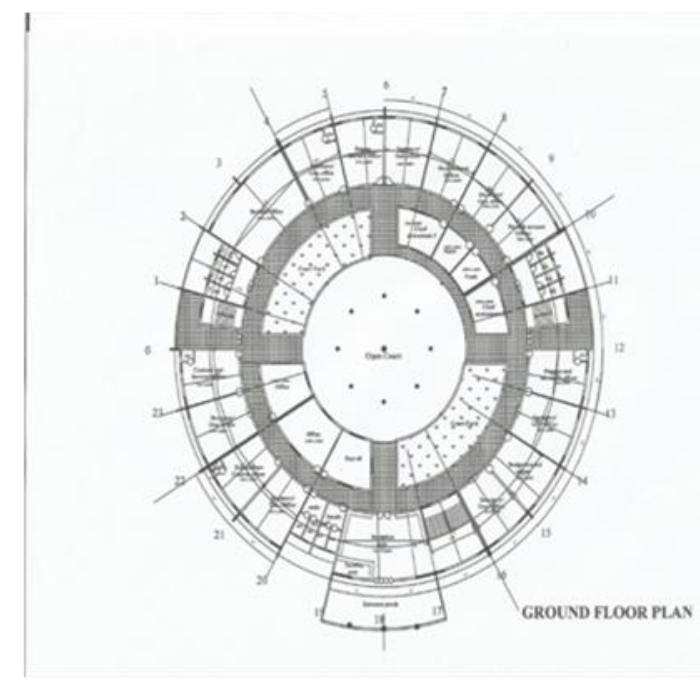

Showing the Ground floorplan of LAUTECH Senate Building Source: Author's Field Survey, 2017

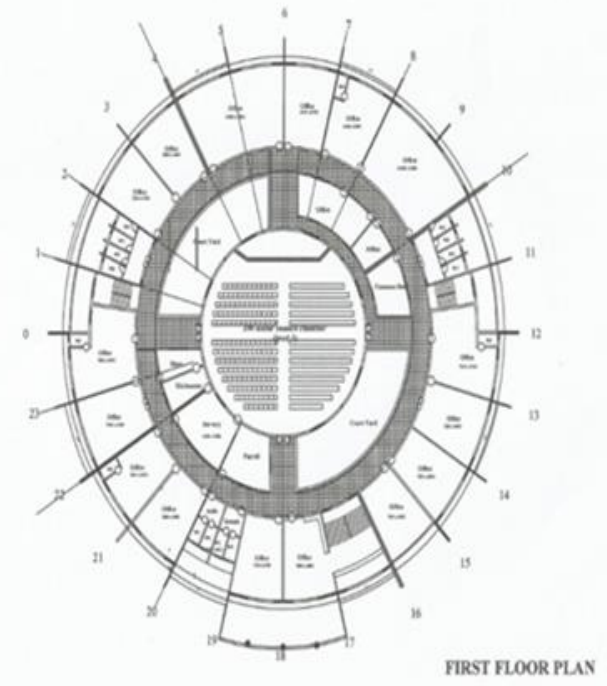

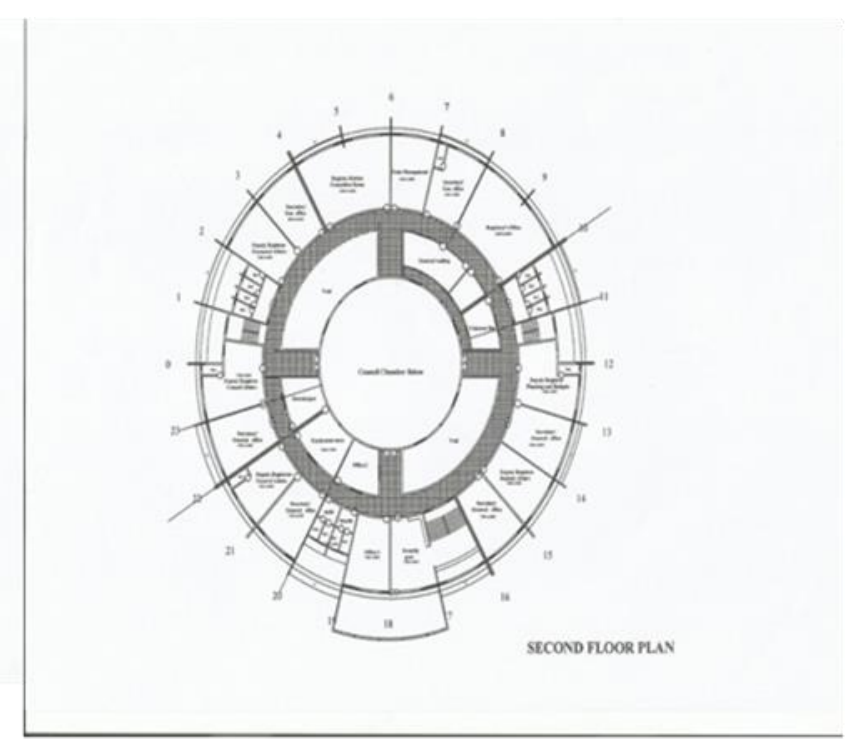

First Floor Plan of LAUTECH Senate Building Source: Author's Field Survey, 2017

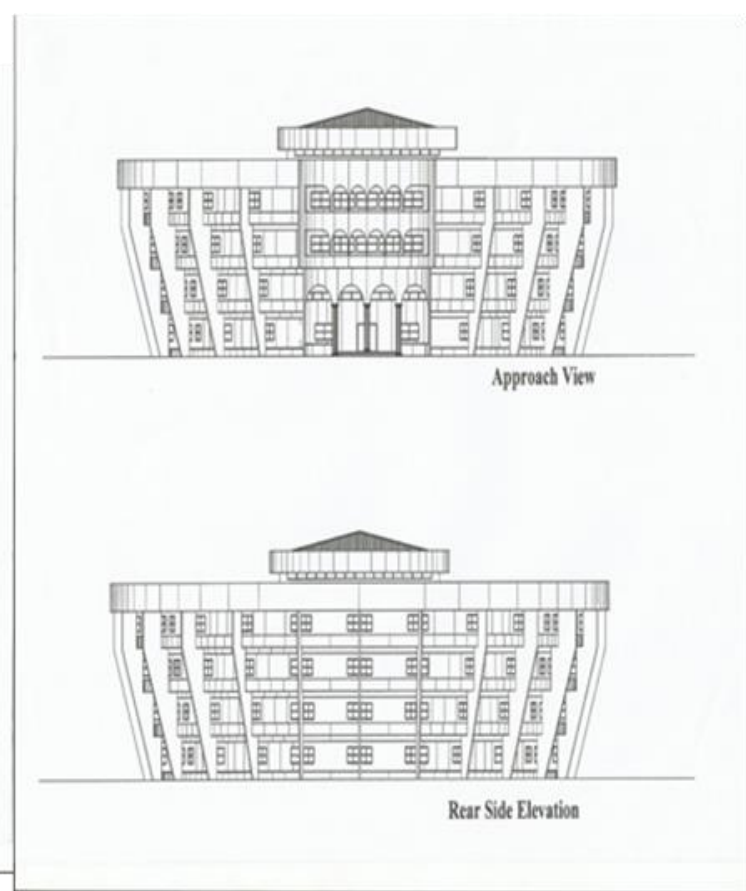

Approach and Rear Elevation of LAUTECH Senate Building Source: Author's Field Survey, 2017 


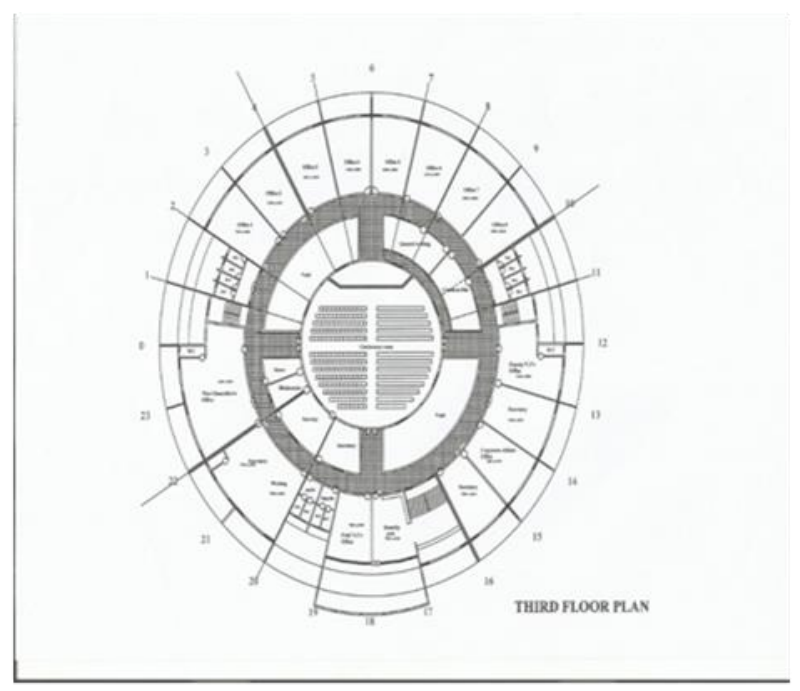

Thind Floor Plan of LAUTECH Senate Building

Source: Author's Field Survey, 2017

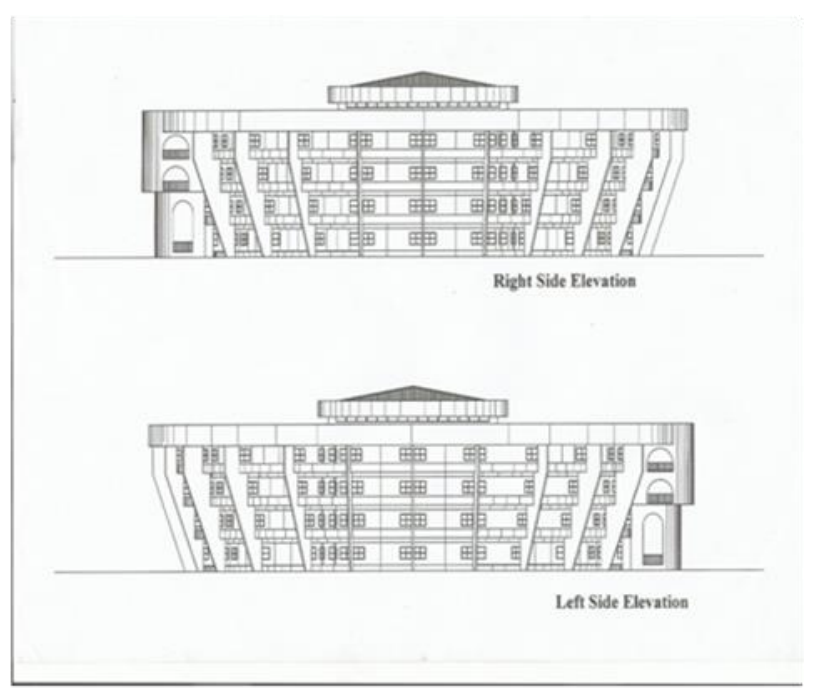

Right and Left side Elevation of LAUTECH Senate Building Source: Author's Field Survey, 2017

Objective: To analyse the user's perception of the ventilation condition in the study area.

Table 1: Easiness in Operation of Window Type

\begin{tabular}{lllll}
\hline & Projected (\%) & Sliding (\%) & Casement (\%) & Total (\%) \\
\hline OAU SENATE BUILDING & 0 & 0 & 100 & 100 \\
LAUTECH SENATE BUILDING & 0 & 100 & 0 & 100 \\
UI SENATE BUILDING & 96.7 & 0 & 3.3 & 100 \\
UNILAG SENATE BUILDING & 0 & 0 & 100 & 100 \\
TOTAL (\%) & 96.7 & 100 & 203.3 & 300 \\
TOTAL AVERAGE \% & 24.17 & 25.0 & 50.82 & 100 \\
\hline
\end{tabular}

SOURCE: Author's fieldwork April, 2017.

It is important to know the perception of respondents regarding the easiness of operation of the window and preferred window type in their offices. From the result in table 4 above, it can be deduced that casement window type was most preferred with $50.82 \%$ followed by Sliding window with $25.0 \%$ while projected window has $24.17 \%$. Subsequently, the finest of all window types is casement window since it offers a number of operable alternatives such as push-out, top-down grille, flat, top and no grill. It can be customized for exact size and wanted size and colour, and they look appealing in a number of materials. Ordinary casement window materials incorporate wood, steel, clad, fibreglass, aluminium, and vinyl. Casement windows will subsequently be proposed since it opens apparently not at all like others it is broadly open from top to bottom and side-to-side, giving great natural ventilation and openness to strong blast of wind.

Table 2: Window Type Preferred

\begin{tabular}{lllll}
\hline & Projected (\%) & Sliding (\%) & Casement (\%) & Total (\%) \\
\hline OAU SENATE BUILDING & 0 & 0 & 100 & 100 \\
LAUTECH SENATE BUILDING & 0 & 100 & 100 & 100 \\
UI SENATE BUILDING & 96.7 & 0 & 3.3 & 100 \\
UNILAG SENATE BUILDING & 0 & 0 & 100 & 100 \\
TOTAL (\%) & 96.7 & 0 & 103.3 & 300 \\
TOTAL AVERAGE \% & 24.17 & 25 & 75.82 & 100 \\
\hline
\end{tabular}

SOURCE: Author's fieldwork April, 2017. 
The choice of respondents regarding the preferred window type that should be considered in specifying window types for an office building. From the result in table 5 above, it is revealed that casement window type was most preferred with $75.82 \%$ followed by Sliding window with $25.0 \%$ while projected window has $24.17 \%$. The study further showed that the majority of the users $(75.82 \%)$ preferred the casement window type because of its easiness in operation to other window types. Casement windows will therefore be any proposed Senate Building or Office Building in the Study area.

Table 3: Types of Window Used

\begin{tabular}{|c|c|c|c|c|c|c|c|c|c|c|c|c|}
\hline \multirow[b]{2}{*}{ Selected } & \multicolumn{3}{|c|}{$\begin{array}{l}\text { Windows types } \\
\text { Louvre Window }\end{array}$} & \multicolumn{3}{|c|}{ Projected Window } & \multicolumn{3}{|c|}{ Sliding Window } & \multicolumn{3}{|c|}{ Casement } \\
\hline & Typ. & Reg. & V.C's & Typ. & Reg. & V.C's & Typ. & Reg. & V.C's & Typ. & Reg. & V.C's \\
\hline Senate & Off. & Off. & Off. & Off. & Off. & Off. & Off. & Off. & Off. & Off. & Off. & Off. \\
\hline \multicolumn{13}{|l|}{ Building } \\
\hline LAUTECH & & & & & & & 101 & 2 & 2 & & & \\
\hline UI & & & & 23 & 2 & 2 & & & & 36 & 2 & 2 \\
\hline UNILAG & 35 & 2 & 2 & & & & & & & 96 & 2 & 2 \\
\hline TOTAL & 35 & 2 & 2 & 119 & 4 & 4 & 101 & 2 & & 132 & 4 & 4 \\
\hline $\begin{array}{l}\text { GROUND } \\
\text { TOTAL }\end{array}$ & \multicolumn{3}{|c|}{$39(9.5 \%)$} & \multicolumn{3}{|c|}{$127(30.0 \%)$} & \multicolumn{3}{|c|}{$105(25.5 \%)$} & \multicolumn{3}{|c|}{$140(34.0 \%)$} \\
\hline
\end{tabular}

Table 6 reveals the distribution of window types in the study area. Most of the windows in the study area are projected window. The table revealed that One hundred and Forty $(34.0 \%)$ of the windows were casement type, one hundred and twenty-seven (30.0 \%) were projected, one hundred and five $(25.5 \%)$ were sliding; while thirty-nine $(9.5 \%)$ were the louvred type. Each university has their peculiar usage of window type. The result shows that when proposing for window type, projected and casement should be considered in constructing senate building. Thus, the result analysis shows that casement is highly acceptable because it is open to a strong blast of wind (Table 6). However, this result supported the outcome of the research done by Iannone and Adebamowo in 1999 and 2004 respectively.

\section{Conclusion and Recommendations}

Physical observation of the window types and location in the selected Senate buildings revealed that 140 (34.0\%) of the windows were casement type; 127 (30.0\%) were Projected; 105 (25.5\%) were sliding; while $39(9.5 \%)$ were the louvred type. However, window heights with respect to the floor (sill height) of all the selected buildings were at the normal $(0.9 \mathrm{~m})$. The study further showed that the majority of the users (73.8\%) preferred the casement window type because of its easiness in operation to other window types. However, this design has gone ahead in solving more than the persisting problem of ventilation and space in the Senate building. Circulation and orientation of building for the avoidance of glare and many more were also solved. The study hereby recommends that with adequate sizes, casement window type is the best for office design and for ventilation comfort. The designer must be aware that the occupants' views must be put into consideration so as to allow for thermal comfort in Senate buildings. This study also informs the policies makers about the orientation and shape of the office buildings to enhance the natural ventilation.

\section{References}

Adebamowo, M. A. (2004). Study of thermal comfort characteristics in some residential buildings designed by Architects in Lagos. Building Quarterly, 2(4), 37-41.

Adunola, A. O. (2006). A study of thermal Comfort in Naturally Ventilated Residential Buildings in Olubadan Estate. Ibadan. An unpublished work for the Degree of Master of philosophy at the Obafemi Awolowo University (OAU), Ile -Ife, Nigeria. 
Ayinla, A. K. (2011). Effects of Natural Ventilation on Residents' Comfort in the Houses of the Traditional Core of Ogbomoso, Nigeria. An unpublished work for the Degree of Master of philosophy at the Obafemi Awolowo University (OAU), Ile -Ife, Nigeria.

Ayinla, A., Adeniyi, S. \& Okeyinka, Y. (2013). Bio-Climatic Characteristics of Residential Building Types in the Traditional Core of Ogbomoso, South West Nigeria International Journal of Science, Environment ISSN 2278-3687 (O) and Technology, 2(6), 1462-1478.

ANSI/ASHARE. (2009). Standard 62.1, Ventilation for Acceptable Indoor Air Quality, Ashare. Inc. Atlanta, GA U.S.A.

Atkinson, J., Chartier, Y. \& Pessoa-Silva, C. L. (2009). Natural Ventilation for Infection Control in Health - Care settings. Geneva: World Health Organization.

Awbi, H. B. (2003). Ventilation of buildings. 2nd ed. New York: Taylor \& Francis.

Bluyssen, P. M., de Oliveira Fernandes, E., Groes, L., Clausen, G. H., Fanger, P. O., Valbjorn, O., Bernard, C. A. \& Roulet, C. A. (1996). European indoor air quality audit project to optimize indoor air quality and energy consumption in office building: Indoor air Journal, 6, 221-338.

Chen, Q. (1996). Prediction of room air motion by Reynolds-stress models. Building and Environment, 31(3), 233-244.

Etheridge, D. \& Sandberg, M. (1996). UK: John Wiley \& Sons.

Fajobi, Kofoworola Joseph. (2004). A design proposal for Senate Building for Bowen University Iwo, Osun. Department of Architecture LAUTECH, Ogbomoso.

Frej, A. (2005). Green Office Buildings: A Practical Guide to Development. The Urban Land Institute, Washington, D. C, 4-8.

Iannone, F. (1999). Natural Ventilation and Sustainability: Designing with Computational Fluid Dynamics. Dipartimento di Architettura e Urbanistica - Politecnico di Bari Via Orabona, 4-70125.

Iannone, F. (1999). Displacement Natural Ventilation Systems Design in large rooms, Simplified models and Numerical evaluation for architectural design. Ancona University.

Nielsen, P. V. (1974). PhD thesis Denmark: Technical University of Denmark. Flow in air-conditioned rooms - model experiments and numerical solutions of the flow equations. 